\title{
XXXVI. The genesis of Dalton's atomic theory
}

\author{
Henry Debus Ph.D. F.R.S.
}

To cite this article: Henry Debus Ph.D. F.R.S. (1896) XXXVI. The genesis of Dalton's atomic theory, Philosophical Magazine Series 5, 42:257, 350-368, DOI: 10.1080/14786449608620927

To link to this article: http://dx.doi.org/10.1080/14786449608620927

曲 Published online: 08 May 2009.

Submit your article to this journal 준

Џll Article views: 3

Q View related articles $₫$ 


\section{The Genesis of Dalton's Atomic Theory. By Henry Debus, Ph.D., F.R.S.**}

GIR H. E. ROSCOE and Mr. A. Harden bave lately $D$ published a book $\dagger$ entitled 'A New View of the Origin of Dalton's Atomic Theory,' with the following introductory remarks :-

"It may seem remarkable that, after the lapse of nearly a century, since John Dalton first applied the atomic theory of matter to chemical phenomena, it should be possible to find anything new respecting the genesis of bis ideas. The explanation is to be found in the unlooked for discovery, in the rooms of the Literary and Philosophical Society of Manchester, where the whole of Dalton's experimental work was carried out, of his Laboratory and Lecture Note-Books contained in a number of manuscript volumes. A careful study of these has led us to conclusions concerning the origin of the atomic theory of Chemistry which differ widely from those which have been generally accepted. It has hitherto been supposed that it was the experimental discovery of the law of combination in multiple proportions which led Dalton, seeking for an explanation of this most remarkable fact, to the idea that chemical combination consists in the approximation of atoms of definite and characteristic weight, the atomic theory being thus adopted to explain the facts discovered by chemical analysis. ... The actual relations are, therefore, precisely the inverse of those which are usually accepted. It was the theory of the existence of atoms of different weights which led Dalton to the discovery of the facts of combination in multiple proportions."

This view of Roscoe and Harden is not new! Two years ago I published a pampletet $\neq$, wherein it is clearly stated that the atomic theory led Dalton to the discovery of the law of multiple proportions. It is gratifying to me that Dalton's Note-books confirm the view expressed by me in May 1894. In the same essay (p. 58), I have shown that several years before Avogadro Dalton had formed the hypothesis that equal volunes of different gases contain under normal conditions of temperature and pressure an equal number of molecules.

* Communicated by the Autbor.

+ 'A New View of the Origin of Dalton's Atomic Theory, a Contribution to Chemical History' by Henry E. Koscoe and Arthur Harden. London: Macmillan \& Co. 1896.

† ' Ueber einige Fundamentalsätze der Chemie, insbesondere das Dalton-Avogadro'sche Gesetz. Eine historische Untersuchung von Dr. Heinrich Debus.' Cassel : Gustav Klaunig, 1894, py. 44-45. 
According to Roscoe and Harden this latter statement of mine is not correct. My argument rests, they assert, on a confusion between the relative density of the atoms and the relative density of the gases made up of these atoms.

I cannot allow Dalton's merits to be set aside in this manner, and I feel at the same time obliged to show that I am not guilty of the mistake attributed to me.

The atomic theory and the law of equal volumes (law of Avogadro) constitute the basis of scientific chemistry. As it is a matter of importance for everyone to know how the foundation of his house has been laid, I believe the following discussion will not be unacceptable to scientific chemists, especially on account of some new matter considered in it. As Dalton's nomenclature and views differ in several points from those now in vogue, a few explanations will be necessary. The elementary gases consist, according to Dalton, of very small, indivisible particles, called atoms. Each atom is surrounded by an atmosphere of heat of from one to two thousand times its own size. Whatever, therefore, may be the shape or figure of the solid atom abstractedly, when surrounded by such an atmosphere it must be globular; but as all the globules in any small given volume are subject to the same pressure, they must be equal in bulk, and will, therefore, be arranged in horizontal strata, like a pile of shot (N.S. 145). The volume of the molecule of a gas is equal to the volume of the solid nucleus plus the volume of the atmosphere of heat. Compound molecules result from the juxtaposition of two or more different atoms. A molecule of oxygen is composed of only one atom of oxygen, a molecule of carbonic oxide of an atom of carbon and one of oxygen. Dalton usually employs the word atom; he calls a molecule of water an "atom of water ;" a molecule of ammonia an "atom of ammonia." I shall express Dalton's ideas in modern phraseology.

\section{Abbreniations.}

N.S. stands for: 'New System of Chemical Philosophy,' by

R.,$\quad$,

0. " "

Al. , " John Dalton. Manc'r ster, 1808-1810. 'A New View of the Origin of Dalton's Atomic Theory,' by H. E. Roscoe and A. Harden. London : Macmillan \& Co., 1896.

Ostwald's Klussiker, No. 8. Leipzig: W. Engelmann.

Alembic Club Reprints, No. 2. Edinburgh: W. F. Clay. 
D. stands for 'Ueber einige Fundamentalsïtze der Chemie, insbesondere das Dalton-Avogadro'sche Gesetz'; von Dr. Heinrich Debus. Cassel : Gustav Klaunig, 1894.

$\begin{array}{lll}\mathrm{M} & , & , \\ \mathrm{S} & , & , \\ \mathrm{M} / \mathrm{S} & , & \end{array}$
Molecular Weight.

Specific gravity.

Molecular volume.

Division of numbers is expressed thus, $\mathrm{M} / \mathrm{S}$ :

$$
\frac{\mathrm{M}}{\mathrm{S}}=\mathrm{M} / \mathrm{S} \text {. }
$$

(p. ...)

page ... in this paper.

The empirical law that equal volumes of different gases contain, at normal temperatures and pressure, an equal number of molecules will be represented by the symbols $\mathrm{M} / \mathrm{S}=\mathrm{C}$.

\section{Dalton's Atomic 'Theory.}

The opinion used to be common amongst chemists * that Dalton had originated the idea of indivisible particles (atoms) for the explanation of the law of multiple proportions. This, however, is not the case. The idea that the objects of observation are aggregates of exceedingly small indivisible particles is older than science itself; it is attributed to a Phenician philosopher, Moschus, living at Sidon at about 1100 в.c. (D. 35). His views, developed by the Greeks, were forgotten after the destruction of the Roman empire, but resuscitated by Gassendi about the middle of the 17th century. Boyle, who called the atomic hypothesis the Phenician philosophy $\dagger$, applied it to the explanation of chemical phenomena, and Newton to the explanation of Boyle's law. Also the chemists of the last century employed the atomic doctrine for the illustration of chemical change (D. 38-40). Dalton, who seems to have obtained the idea of atoms from Newton (R. 13, 123), applied it, almost from the beginning of his scientific career, to the explanation of physical phenomena, such as diffusion, absorption, and expansion. In 1803 he discovered a method how to determine the relative weight of atoms, and added to the atomic philosophy a series of principles. The group of principles so added by Dalton I propose to call Dalton's "atomic theory."

The main points are :-

* Liebig, Handbuch der Chemie, Heidelberg, 1843, p. 65.

† 'The Works of the Right Hon. Robert Boyle.' London, 1744, vol. i. p. 228. 
(1) When only one combination of two bodies, A and B, can be obtained, it must be supposed to be a binary one, a compound of one atom of $A$ with one atom of $B$, unless some cause appear to the contrary.

(2) When two combinations are known, they must be presumed to be a binary $(A+B)$ and a ternary $\left(A_{2}+B\right)$ or $\left(\mathrm{A}+\mathrm{B}_{2}\right)$.

(3) When three combinations are obtained, we may expect one to be a binary and the other two ternary.

(4) When four combinations are observed, we should expect one binary, two ternary, and one quaternary $\left(A_{3}+B\right)$ or $\left(A+B_{3}\right)$.

(5) A binary compound should always be specifically heavier than the mere mixture of its two ingredients.

(6) A ternary compound should be specifically heavier than the mixture of a binary and a simple which would, if combined, constitute it; \&c.

(7) The above rules and observations equally apply when two bodies, such as $(\mathrm{C}+\mathrm{D})$ and $(\mathrm{D}+\mathrm{E})$ are combined (N.S. 214).

The question is : How did Dalton arrive at these principles? Roseoe and Harden think that the answer to this question is contained in some notes which Dalton had written down for a lecture delivered in London on Jan. 27th, 1810 (R. 13).

The pertinent passages of the notes are as follows:-

"As the ensuing lectures on the subject of chemical elements and their combinations will perhaps be thought by many to possess a good deal of novelty as well as importance, it may be proper to give a brief historical sketch of the train of thonght and experience which led me to the conclusions about to be detailed.

"Having been long accustomed to make meteorological observations, and to speculate upon the nature and constitution of the atmosphere, it often struck me with wonder how a compound atmosphere, or a mixture of two or more elastic fluids, should constitute apparently a homogeneous mass, or one in all mechanical relations agreeing with a simple atmosphere."

In explanation of the foregoing remarks it may be mentioned that the molecules of all gases, therefore the atoms of the constituents of the atmosphere, oxygen and nitrogen, were at the time assumed by Dalton to be of equal volume : in other words, equal volumes of oxygen and nitrogen gas would, under normal conditions, contain an equal number of molecules (N.S. 188). Hence the specific gravity of an atom of Phil. Mag. S. 5. Vol. 42. No. 257. Oct. 1896. $2 \mathrm{C}$ 
oxygen must be greater than the specific gravity of an atom of nitrogen.

This view, in connexion with the general theory of gases then in vogue, led to the conclusion that, in a mixture of oxygen and nitrogen, the heavier atoms of oxygen ought to form a layer at the bottom of the vessel and the lighter nitrogen atoms a separale layer at the top.

Experiments, on the other hand, proved that air, taken from different heights, was of uniform composition. Dalton also found that a lighter gas, placed above a heavier gas, will gradually diffuse downwards (N.S. 151). To explain these observations a weak chemical affinity was assumed between the molecules of different gases. The globular molecules Dalton considered to be arranged like a pile of shot (N.S. $145,147)$, and as all the molecules are subject to the same pressure and exert the same counter-pressure, they must be all, independent of their nature, of the same size (N.S. 188),

$$
M / S=M^{\prime} / S^{\prime}=M^{\prime \prime} / S^{\prime \prime}=M^{\prime \prime \prime} / S^{\prime \prime \prime} \text {. }
$$

The air is composed of 77.88 vols. of nitrogen, 21.2 vols. of oxygen, and 0.066 vol. of carbonic acid. Hence, according to the above law, for every molecule of carbonic acid there are 31.8 mols. of oxygen and 118 mols. of nitrogen present in our atmosphere.

Now, if a weak chemical affinity is the couse of diffusion, then compounds of a very conplicated nature must result. This appeared to Dalton very improbable, and accordingly he rejected the chemical explanation of the diffusion of gases.

Dalton goes on with his notes as follows :-

"In the year 1801 I hit upon an hypothesis (N.S. 153) which completely obviated these difficulties. According to this, we were to suppose that the atoms of one kind did not repel the atoms of another kind, but only those of their own kind. This hypothesis most effectually provided for the diffusion of any one gas through another, whatever might be their specific gravities, and perfectly reconciled any mixture of gases to the Newtonian theorem (R. 15). Every atom of both or all the gases in the mixture was the centre of repulsion to the proximate particles of its own kind, disregarding those of the other kind. All the gases united their effort in counteracting the pressure of the atmosphere, or any other pressure that might be opposed to them. This hypothesis, however beautiful might be its application, had some improbable features. We were to suppose as many distinct kinds of repulsive power as of gases ; and, moreover, to suppose 
that heat was not the repulsive power in any one case; positions certainly not very probable.

"Upon reconsidering this subject, it occurred to me that I had never contemplated the effect of difference of size in the particles of elastic fluids, or when the expression $\mathrm{M} / \mathrm{S}=\mathrm{C}$ is of different value for different gases. And if the sizes be different, then on the supposition that the repulsive power is heat, no equilibrium can be established by particles of unequal sizes pressing against each other.

"This idea occurred to me in 1805. I soon found that the sizes of the particles of elastic fluids must be different. For a mensure of azotic gas and one of oxygen, if chemically united, would make nearly two mensures of nitric oxide, and those two could not have more molecules of nitric oxide than one measure had of oxygen or nitrogen.

"Hence the suggestion that all gases of different kinds have a difference in the size of their molecules; and thus we arrive at the reason for that diffusion of every gas through every other gas, without calling in any other repulsive power than the well-known one of heat.

"This then is the present view which I have of the constitution of a mixture of elastic fluids (year 1810). The different sizes of the particles of elastic fluids under like circumstances of temperature and pressure being once established, it became an object to determine the relative sizes and weights, together with the relative number of atoms in a given volume. This led the way to the combinations of gases, and the number of atoms entering into such combinations, the particulars of which will be detailed more at large in the sequel ....." (R. 13-17).

From these statements of Dalton, Roscoe and Harden deduce the following genesis of the atomic theory :-

"The balance of evidence is, therefore, strongly in favour of the statement made in London by Dalton himself in 1810, that he was led to the atomic theory of chemistry in the first instance by purely physical considerations in opposition to the view hitherto held by chemists, that the discovery by Dalton of the fact of combination in multiple proportions led him to devise the atomic theory as an explanation. It, therefore, becomes necessary for us to modify our view as to the foundation of the atomic theory. There seems to be no doubt that the idea of atomic structure arose in Dalton's mind as a purely physical conception, forced upon him by his study of the physical properties of the atmosphere and other gases. Confronted, in the course of his study, with the problem of ascertaining the relative diameters of the par. $2 \mathrm{C} 2$ 
ticles, of which, he was firmly convinced, all gases were made up, he had recourse to the results of chemical analysis. Assisted by the assumption that combination always takes place, in the simplest possible way, he thus arrived at the idea that combination takes place between particles of different weights, and this it was which differentiated his theory from the historic speculations of the Greeks. The extension of this idea to substances in general necessarily led him to the law of combination in multiple proportions, and the comparison with experiment brilliantly confirmed the truth of his deduction" (R. 49-51).

The problem of ascertaining the relative diameters, or rather the relative volumes, of the molecules of different gases, led Dalton, according to Roscoe and Harden, to the invention of the atomic theory. In the pamphlet mentioned before (p. 350), I have stated that Dalton wished to verify the hypothesis $\mathrm{M} / \mathrm{S}=\mathrm{C}$, viz. to ascertain whether the molecular volumes of different gases are of equal or of different magnitudes. For this purpose he required to know the respective molecular and atomic weights. This necessity led him to the formation of the atomic theory (D. 58).

I am much pleased to observe that, with regard to the problem which originated the atomic theory, Roscoe and Harden, after a careful study of Dalton's note-books, arrive at the same view which I published two years ago, but I regret very much that I cannot approve the reasons which have guided their judgment.

The tirst assertion of Roscoe and Harden, "the balance of evidence is, therefore, strongly in favour of the statement made in London by Dalton himself in 1810 , that he was led to the atomic theory of chemistry, in the first instance, by purely physical considerations," I have not met, nor do I remember to have seen in any of Dalton's writings, nor am I. able to deduce such an assertion from Dalton's notes, quoted before. These notes treat of two distinct subjects, the theories of gaseous diffusion and the problems of the atomic theory. The description passes abruptly from the one to the other without any connecting link. How did Dalton get over the chasm which separates the two? We want to know the genesis of Dallon's methods of determining atomic veights. This, the essence of the matter, Messrs. Roscoe and Harden pass over in silence!

Dalton explained the diffusion of gases on the assumption that the molecules of different gases are not of the same size. The question, therefore, was, Are the molecules of different gases really of unequal volume? "I soon found," says 
Dalton," that the sizes of the particles of gases must be different. For a measure of azotic gas and one of oxygen, if chemically united, would make nearly two measures of nitric oxide, and those two could not have more atoms (molecules) of nitric oxide than one measure had of azote or oxygen. Hence the suggestion that all gases of different kinds have a difference in the size of their molecules; and thus we arrive at the reason for that diffusion of every gas through every other gas ...." (R. 16-17). The old view of Dalton, that in gases the force of cohesion is quite overcome by the force of repulsion, and that, in consequence, the particles of the elementary gases consist of single atoms, would lead to the conclusion which he drew from the volumetric proportions of nitrogen and oxygen in nitric oxide, without requiring the atomic theory as described on p. 353.

Passing on to the atomic theory we have the remarks:"The different sizes of the particles of gases, under like circamstances of temperature and pressure, being once established, it became an object to determine the relative sizes and weights together with the relative number of atoms in a given volume."

If we remember that these quotations are not from a running narrative, but from notes intended for a lecture, where the lecturer could at any moment make verbal explanations and additions, then we may ask whether, between the notes on the diffusion of gases and those on the atomic theory, there is, or there is not, a connexion similar to the one between cause and effect, as Roscoe and Harden assume? On this point Dalton is absolutely silent. We wish to know the origin of the methods by means of which Dalton determined the size, weight, and numbers of the atoms; and we cannot discern how he arrived at these methods from his theory of gaseous diffusion. Messrs. Roscoe and Harden do not say one word on this subject. May not Dalton have been engaged in the calculation of molecular and atomic weights and molecular volumes before he recognized that the size of the molecules of different gases MUST be different? A few facts show that he was so engaged.

The idea of considering the influence of the size of the molecules on diffusion occurred to Dalton, according to his own statement, in 1805 . The result of his consideraiion was the abandonment of the theory of diffusion formed in 1801 (described on pp. 354, 355), and the formation of a new view, which ascribed diffusion to difference of size of the molecules of the diffusing gases.

This new view is, according to Roscoe and Harden, the source of Dalton's atomic theory. If so, then the atomic 
theory cannot have been formed before the year 1805. But Roscoe and Harden found in Dalton's note-book a table of atomic weights dated the 6th of September, 1803. This date shows that the theory is at least two years older than it ought to be according to Roscoe and Harden's view (R. 2y). In order to get over this difficulty, they assume (R. 25) that Dalton committed a clerical error by writing 1805 instead of 1803 in bis description of the formation of the theory of diffusion based on an unequal size of the particles. Dalton does not say that the theory of diffusion led him to the con. ception of the atomic theory. The statement that it did do so is only an inference of Messrs. Roscoe and Harden. Therefore they are not justified in attributing a clerical error to him, and transferring the conception of the theory of diffusion from 1805 to 1803 .

Dalton's paper, "Experimental Enquiry into the Proportions of the several Gases or Elastic Fluids constituting the Atmosphere," was printed in the 'Memoirs of the Literary and Philosophical Society of Manchester,' second series, vol. i. 1805, under Dalton's supervision as Secretary of the Society (R. 31). We have in this paper the following remarks on the principle that the elastic or repulsive power of each molecule is confined to its own kind :- "This principle accords with all experience, and, I have no doubt, will soon be perceived and acknowledged by Chemists and Philosophers in general" (Al. 5). Now this principle is the principle of the theory of diffusion formed in 1801 (pp. 354, 355); consequently he must have still held this theory in $\mathbf{1 8 0 5}$, at the time when the paper was printed, and the theory of diffusion which superseded it must have been formed at a later period in the year 1805 . Therefore this later theory of the diffusion of gases cannot bave been the origin of the atomic theory of 1803 . The conclusion we arrive at is : "The opinion of Roscoe and Harden that the theory of the diffusion of gases of 1805 leả Dalton to the conception of his atomic theory is not in accordance with facts."

II. The Genesis of Dalton's Atomic Theory.

The notes published by Roscoe and Harden enable me to render my view of the genesis of this theory, described on p. 356 (D. 58), more accurate and complete.

In order to explain equilibrium in a mixture of gases, Dalton had adopted, in the year 1801 , the hypothesis $\mathrm{M} / \mathrm{S}=\mathrm{C}$. But he was not able for several years to test his conception by experiments, as no method was known for the determination of $M$, the molecular weight. The desire to discover such a method made him, probably, very observant of all circumstances which could promote his wish (N.S. 187-188). 
Two factors determine every great advance in science-a fact, and a mind prepared for the full and complete appreciation of the fact. Moreover, the fact must be at hand when it is wanted by the mind. These conditions were satisfied when Galileo observed the oscillating lamp in the Cathedral of Pisa; when Newton saw the falling apple; when Malus observed the ray reflected from the window of the Luxembourg; when Lavoisier was informed of the discovery of oxygen by Scheele and Priestley (D. 20-21).

The discovery of oxygen is the great fact with which the history of scientific chemistry commences ; but neither of the discoverers-neither Priestley nor Scheele-recognized the significance of the discovery. Lavoisier's mind was the good soil wherein the seed bore fruit, because it was well prepared by a careful repetition of the experiments of Black and Mever. These experiments prove that carbonates are combinations of a gas which can be transferred from one base to another. Quicklime absorbs carbonic acid from the atmosphere and turns into carbonate of lime. 'I'hese facts raised in Lavoisier's mind the question : Do metals absorb a gas from the atmosphere during calcination? The answer from his own experiments was a decided "Yes." Bui as he could not prepare the gas absorbed, the investigation could not proceed. Then, just at the right moment, Scheele and Priestley informed Lavoisier of the discovery of oxygen, and the antiphlogistic chemistry was born (D.21).

Dalton, the meteorologist, wished to determine the composition of the atmosphere. For this purpose he tried the absorption of oxygen with nitric oxide. In his note-book occurs the following memorandum, dated August 4th, 1803:-

"It appears, too, that a very rapid mixture of equal parts of common air and nitric oxide give 112 or 120 residuum. Consequently, that oxygen joins to nitric oxide sometimes $1 \cdot 7: 1$ or at other times $3 \cdot 4: 1$ " (R. 38, Al. 8).

In the Essay on the Composition of the Atmosphere occurs the remark, "These facts clearly point to the theory of the process ; the elements of oxygen may combine with a certain portion of nitric oxide, or with twice that portion, but with no intermediate quantity" (R. 33, Al.9).

A month after the date of the above note, on September 6 th, 1803, the note-book contains a list of atomic weights (R. 29), and on the 19th of the same month the diameters of the molecules of a certain number of gases were written down (R. 41).

May we venture to conclude, on the strength of these facts, that the observations of the proportions in which nitric oxide and oxygen combiue over water originated in Dalton's mind 
the idea that the atoms combine chemically only according to very small numbers-one atom of $A$ with one, two, or three atoms of $B$ ? There are strong reasons in support of this conclusion. Dalton, who for some years had held the hypothesis $\mathrm{M} / \mathrm{S}=\mathrm{C}$ (N.S. 188), who was accustomed to explain expansion, diffusion, solution, \&c., in a mechanical way by means of the old atomic theory, as Boyle' did 120 years before Dalton's time, was naturally led by the observation of the combining proportions of oxygen and nitric oxide to the view that in simple compounds one atom of $\mathrm{A}$ is united to one or two atoms of B. His previous speculations and observations (p. 354) had prepared him for this conception, and once the idea was formed the transition to the tenets described on p. 353 was easy. Proust and others had made observations like Dalton, but to none had this explanation occurred.

Dalton wished to verify the hypothesis $\mathrm{M} / \mathrm{S}=\mathrm{C}$; for this My present view of the origin of Dalton's atomic theory purpose he endeavoured to find methods for the determination of the atomic and molecular weights. The observations of the combining proportions of nitric oxide and oxygen suggested to him a principle which enabled him to form such methods.

In judging this view, one has to remember that the observations on the combining proportions of oxygen and nitric oxide noted on August 4th, 1803, were followed within a month by calculations of atomic weights and the diameters of atoms and molecules. (R. 38 and 4I.)

\section{Roscoe and Harden's Critique.}

The first part of my view of the genesis of Dalton's atomic theory, described above, is, according to Roscoe and Harden, not correct. They say :-

"The view expressed by Debus, that the use of the term specific gravities by Thomson in his account of the atomic theory implied the acceptance of the law $M / S=C$ by Dalton in 1804 , is also seen to be incorrect. Dalton expressly states in 1803 (R. 27) that the specific gravities of different gases and the specific gravities of their particles are not the same thing. He never appears to have believed in the law $M / S=C$, and this only occurred to him as a possible alternative, at once shown to be inconsistent with fact, to the statement which he recognized as the true one, viz. that no two gases agree in the size of their particles" (R. 47).

In order to form a correct opinion of the assertions contained in this quotation, we nust go back and consider the statements of Dalton on which these assertions are founded. 
Dalton, in his Note-book, i. p. 246 (R. 27), has the following memorandum :-

"Though it is probable that the specific gravities of different elastic fluids (gases) has some relation to that of their ultimate particles, yet it is certain that they are not the same thing; for the ulterior particles of water or steam are certainly of greater specific gravity than those of oxygen, yet the last is heavier than steam."

Instead of building on the dictum contained in this quotation weighty conclusions, as Messrs. Roseoe and Harden do, I confess that I do not understand it. What is the difference between the specific gravity of a gas and that of one of its ulterior particles or molecules? According to Dalton, the molecular volume is $=M / S$ (N.S. 226, note). The specific gravity of a molecule, $s$, is expressed by the quotient of the molecular weight and molecular volume :

$$
\frac{\text { Molecular weight }}{\text { Molecular volume }}=\frac{M}{\bar{M} / \mathrm{S}}=\mathrm{S}=s .
$$

Hence, $\mathrm{S}$, the specific gravity of the gas, $=s$, the specific gravity of one of its molecules; or, in other words, both are the same thing. This result follows from Dalton's definition of the molecular volume, and is opposed to his assertion that the specific gravities of gases and the specific gravities of their molecules are not the same thing, and also to the conclusions of Roscoe and Harden, based on this erroneous assertion. Therefore it does not follow that Dalton did never believe in the hypothesis $\mathrm{M} / \mathrm{S}=\mathrm{C}$, or that the first part of my view stated on p. 360 is incorrect.

Messrs. Roscoe and Harden assert that he (Dalton) "never appears to have believed in the law of equal volumes (hypothesis $\mathrm{M} / \mathrm{S}=\mathrm{C}$ ), and this only occurred to him as a possible alternative, at once shown to be inconsistent with fact, to the statement which he recognized as the true one, viz. that no two gases agree in the size of their particles" (R.47).

What does Dalton himself say on this subject?-" At the time I formed the theory of mixed gases (year 1801) I had a confused idea, as many have, I suppose, at this time, that the particles of gases are all of the same size, that a given volume of oxygen contains just as many particles as the same volume of hydrogen" (N.S. 188). And with regard to the statement "that no two gases agree in the size of their particles," he says, "This idea occurred to me in 1805." Therefore the idea that a given volume of oxygen contains just as many particles as the same volume of hydrogen occurred to Dalton at least four years before the time at which he recognized 
"that no two gases agree in the size of their particles." Consequently, the first idea (M/S = C) did not " occur to him only as a possible alternative, at once shown to be inconsistent with fact, to the statement which he recognized as the true one, viz. that no two elastic fluids agree in the size of their particles," but was held by Dalton, more or less, from $1 \times 01$ to 1805, and only abandoned when he could not bring it into agreement with his later atomistic views.

It bas been shown on p. 361 that the memorandum in Dalton's Note-book, i. p. 246, is not correct, and that the specific gravity of a gas and the specific gravity of one of its molecules are the same thing. But how, we may ask, could Dalton contradict his own definition? On p. 260 of his Note-book, i. (R. 42), occurs a table with the following heading:-" The molecules of gases arranged according to their specific gravities ;" and then follow in arithmetical order the molecular weigbts of eleven gases. The specific gravity of the molecules and the molecular weights are therefore expressed by the same number.

If $M$ represents the molecular weight, $s$ the specific gravity, and $v$ the volume of a molecule, we have

$$
\mathrm{M} / v=s .
$$

As $\mathrm{M}$ is put $=s, v$ must be $=1$; and as this relation is assumed to be general, all gases have the same molecular volume, or $\mathrm{M} / \mathrm{S}=\mathrm{C}$. Hence the molecular weight and the specific gravity of a molecule are then, according to the table, "the same thing."

If we now substitute in Dalton's memorandum quoted on p. 361 , which is not intelligible by itself, for the words "specific gravities of molecules" the words " molecular weights," we obtain :- "Though it is probable that the specific gravities of different elastic fluids (gases) has some relation to their molecular weights, yet it is certain that they are not the same thing" (R. 27) -a perfectly intelligible statement.

Therefore, on p. 246 of Note-book, i., the hypothesis $\mathrm{M} / \mathrm{S}=\mathrm{C}$ is rejected, and on p. 260 accepted.

How are these contradictory statements to be explained?

On p. 188 of bis celebrated work, 'New System of Chemical Philosophy,' Dalton says :-" At the time I formed the theory of mixed gases, I had a confused idea, as many have, I suppose, at this time, that the particles of gases are all of the same size." Consequently there was a time when Dalton believed in the hypothesis $M / S=C$, and his endeavour was to verify the same by experiment. Accordingly, he lost no time in calculating $M$ for oxygen and steam, as soon as he bad 
formed his atomic theory. According to this theory, the molecular weight of steam ought to be greater than the molecular weight of oxygen, and this result in connexion with the hypothesis $M / S=C$ would require the specific gravity of steam to be greater than the specific gravity of oxygen. Experiments gave opposite resuits; they made the specific gravity of oxygen greater than the specific gravity of stean. Hence, one of the two-the new atomic theory or the hypothesis $\mathrm{M} / \mathrm{S}=\mathrm{C}-$ must be wrong. Dalton rejected the latter (Notebook, i. p. 246).

'The extension of the investigation to other gases, however, furnished several examples which gave nearly the same value for $\mathrm{M} / \mathrm{S}=\mathrm{C}$. Note-book, i. p. 258 (R. 41), contains a table of 12 gases with their specific gravities and Dalton's molecular weights. I have recalculated the specific gravities on the unit of hydrogen, and in place of the diameters of molecules calculated by Dalton I have deemed it sufficient to give the molecular volume, M/S.

\begin{tabular}{|c|c|c|c|}
\hline Name of the gas. & $\begin{array}{c}\text { Molecular } \\
\text { Weight. }\end{array}$ & $\begin{array}{l}\text { Specific } \\
\text { Gravity. }\end{array}$ & $\mathrm{M} / \mathrm{S}$. \\
\hline Hydrogen ..... & 1 & 1.00 & 100 \\
\hline Oxygen ........... & $5 \cdot 66$ & $14 \cdot 60$ & 038 \\
\hline Nitrogen .................. & $4 \cdot 00$ & $12 \cdot 5$ & 0.32 \\
\hline Nitrous oxide ........................... & $13 \cdot 66$ & $20 \cdot 9$ & $0 \cdot 65$ \\
\hline Nitric oxide......................... & $9 \cdot 66$ & $14 \cdot 3$ & 067 \\
\hline 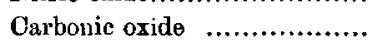 & $10 \cdot 10$ & 130 & $0-77$ \\
\hline Carbonic acid ..................... & $15 \cdot 70$ & $19 \cdot 5$ & 0.80 \\
\hline 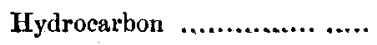 & $5 \cdot 40$ & $8 \cdot 6$ & 063 \\
\hline 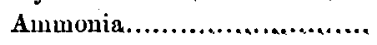 & $5 \cdot 00$ & $7 \cdot 5$ & 0.66 \\
\hline Sulphurous acid ................... & $20 \cdot 00$ & $29 \cdot 0$ & 069 \\
\hline Sulphuretted hydrogen .......... & $15 \cdot 40$ & 140 & $1 \cdot 1$ \\
\hline Steam & $6 \cdot 66$ & $9 \cdot 0$ & 074 \\
\hline
\end{tabular}

The values of M/S are not equal for the different gases, but may be arranged in three groups :-

I. M/S.

Nitrogen ... 0.32

Oxygen....... 0.38
II.

M/S.
III.

$\mathbf{M} / \mathbf{S}$.

\begin{tabular}{|c|c|c|}
\hline Hydrocarbon ......... & 063 & Hydrogen ... \\
\hline Nitrous oxide .......... & 065 & Sulphuretted \\
\hline 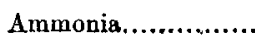 & $0 \cdot 66^{2}$ & lod \\
\hline Nitric oxide............. & $0-67$ & \\
\hline Sulphurous acid ..... & $069\left(\mathrm{SO}_{2}\right)$ & \\
\hline Steam $\ldots . . . \ldots \ldots \ldots \ldots$ & 074 & \\
\hline Carbonic oxide ...... & $0 \cdot 77$ & \\
\hline Carbonic acid ......... & $0.80\left(\mathrm{CO}_{2}\right)$ & \\
\hline
\end{tabular}


The values of $\mathrm{M} / \mathrm{S}=\mathrm{C}$ are dependent on the specific gravities, the chemical composition, and the theories about the constitution of gases. The composition of water is, according to Lavoisier, $85 \mathrm{pts}$. of oxygen and $15 \mathrm{pts}$. of hydrogen, according to Gay-Lussac and Humboldt $87 \cdot 4$ pts. of oxygen and $12 \cdot 6$ pts. of hydrogen. Lavoisier's numbers make the atomic weight of oxygen $=5 \cdot 66$, Gay-Lussac's and Humboldt's $=7$. The errors of observation in 1)alton's time were so considerable that he might have assumed for from 50 to 66 per cent. of the gases in the above list the same molecular volume. The numbers obtained for $\mathrm{M} / \mathrm{S}=\mathrm{C}$, therefore, le! $\mathrm{t}$ it undecided whether the hypothesis, that equal volumes of different gases contain the same number of molecules, is true or not true. The probabilities are, perhaps, sligbily in favour of the hypothesis. This seems to have cansed Dalton to return to his old view, that the particles of gases are all of the same size, or $\mathrm{M} / \mathrm{S}=\mathrm{C}$. This is my explanation of the contradictory statements on two pages, 246 and 260 , of his Note-book, i. (R. 27, 42) (pp. 361,362). The near agreement of several of the numbers of $\mathrm{M} / \mathrm{S}$ in the last table caused a series of new experimental investigations. Dalton, who up to this time had done very little practical work in chemistry, now began with great zenl to determine the composition of important substances, such as ammonia, marsh-gas, and olefiant-gas. The results of these investigations, as far as they concern gases, are collected in a table at the end of the second part of the New System.

Five out of 16 gases, or 31 per cent., and if errors of observation of 2 per cent. are allowed three more, or, together, 50 per cent. of the gases examined, possess the same molecular volume. Dalton's experiments have not explained why 50 per cent. of the gases examined do not conform to the hypothesis $M / S=C$, and they could not do so, the chemical knowledge of the day not being sufficiently advanced. As a matter of fact, it has required the practical work of half a century to convert the hypothesis $\mathrm{M} / \mathrm{S}=\mathrm{C}$ into an empirical law.

Thomas Thomson, the author of the celebrated work " System of Chemistry,' himself a chemist of eminence, paid a visit to his friend Dalton in August 1804. On this occasion the latter communicated to him the principles of the new atomic theory and the results obtained by their application. In 1807 a new edition of the 'System of Chemistry' came out, in which Thomson, with Dalton's permission, published a sketch of the new theory (vol. iii. p. 424). Thomson's deseription is extremely clear and accurate, and Dalton has, as 
far as I know, never taken exception to any of its statements. Now Thomson always calls the relative weight of atoms the "density of atoms." His table of molecular weights is called table of the density of atoms (molecules) (vol. iii. p. 429). Elementary physics teaches that the weights and densities of substances are proportional when the substances under consideration are of the same volume. If we say for density specific gravity, then Thomson's report of Dalton's atomic views, and Dalton's statement in Note-book, i. p. 260 (R. 42) are in perfect agreement. Accordingly, Dalton had not, in August 1804 , thrown the hypothesis $\mathrm{M} / \mathrm{S}=\mathrm{C}$ overboard. He did so in the following year, 1805 , when he could not bring it into agreement with his atomistic views (p. 351) ; and when he found it refractory in this respect, he called it " a confused idea" (N.S. 188).

Messrs. Roscoe and Harden charge me on pp. 10-11 of their book with a "confusion of ideas." They say :- "Debus further argues that when Dalton communicated his theory to Thomson, he must have held the opinion that these two relations, the relative density and the relative weight of the atoms, were identical, or what Debus appears to consider to be the same thing, that the relative densities of the gases were identical with the relative weight of their atoms. . . . On the strength of this argument, which appears to rest, on a confusion between the relative density of the atoms and the relative density of the gases made up of those atoms. ..." I have not asserted that the relative weight and the relative density of the atoms were IDENTICAL. I have expressed myself in the following manner :- "We must conclude that Dalton, at the time when he communicated his ideas to Thomson, considered that the molecular weights of the gases stand to each other in the same ratio as the densities of their molecules" (D. 51). As for the confusion between the relative density of the atoms or molecules and the relative density of the gises made up of those atoms or molecules, I must refer to P. 361, where it bas been shown, if we write for density specific gravity, that according to Dalton's own definition, the specific gravity of a gas is equal to the specific gravity of one of its molecules. Therefore, the confusion is not on my side!

The Italian physicist Ȧmadeo Avogadro became acquainted with Dalton's atomic theory through Thomson's report $(0$. no. 8, p. 7, note). He puts on Thomson's statements the same interpretation as I do. Dalton's object is to find the atomic weights of the elements, and the molecular weights of 
the compounds formed of these elements. The sum of the weights of the atoms in a molecule is his molecular weight.

Avogadro determines the molecular weights directly from the specific gravities of the gases. The molecular weight is, if I may say so, the end of Dalton's and the beginning of Avogadro's work. About the constituents of the molecules, the atoms, Avogadro is absolutely silent. He knows only molecules and parts of molecules. Whether there is or is not a limit to the division of a molecule he does not say. Avogadro treats the subject like a theoretic mechanician, who considers his particles divisible or not, according to the nature of his problem. The unit of Dalton is the indivisible atom, the unit of Avogadro the divisible molecule (D. 70).

It is worthy of notice that Avogadro is not censcious of these differences between Dalton and himself. He criticises Dalton's work as if he and Dalton were engaged with the solution of the same problems, and calling attention to the agreement of some of his results with those of Dalton, he says:- "This agreement is in favour of our hypothesis, which is essentially nothing else but the system of Dalton improved by a sure expedient* to which we have been led by the facts discovered by Gay-Lussac" (0. no. 8, p. 22).

Avogadro could only identify his system with Dalton's on the assumption that both systems rested on the same principle. This principle is the hypothesis $M / S=C$. As Arogadro received his information about Dalton's work from Thomson, it follows that he put the same interpretation on Thomson's words as I have done, and as the latter published his book in the year 1807, and Avogadro bis essay in 1811, it appears highly probable that Avogadro received the first intimation of the hypothesis $\mathrm{M} / \mathrm{S}=\mathrm{C}$ from Dalton. The great merit of Avogadro is founded on his proposal to consider the molecules of the elementary gases divisible into two or more parts, because thereby the hypothesis $\mathrm{M} / \mathrm{S}=\mathrm{C}$ became of practical importance.

But are the hypothetical molecular weights of Avogadro the real molecular weights? This question could only be answered by the synthesis of the molecules from the constituent atoms. The sum of their weights is the molecular weight. Therefore, logically considered, the atomic weights must precede the molecular weights. The determination of the atomic weights was, accordingly, the task of Dalton and his generation. This is the real reason why the hypothesis $\mathrm{M} / \mathrm{S}=\mathrm{C}$ received no attention in Dalton's and Avogadro's time and was soon forgotten. Fifty years later, after

* The division of molecules. 
thousands of vapour densities had been taken, it reappeared in the form of an empirical law.

Chemists have often wondered why Dalton did not acknowledge as correct the observations of Gay-Lussac that gases always combine in simple volumetric proportions. Various improbable or absurd reasons* have been assigned for his reluctance to adopt the results of the distinguished French chemist. The real reason is near at hand. Dalton could not accept Gay-Lussac's law of the combination of gases in simple volumetric proportions, because, if he had done so, he would have abandoned the chief principle of his atomic theory. I will illustrate this assertion by an example. The first principle of Dalton is, that when two elements form only one compound, the compound is a binary one unless some cause appears to the contrary.

Only one compound of hydrogen and oxygen and only one compound of hydrogen and nitrogen were known, hence the formula of the first would be $\mathrm{HO}$ and of the second $\mathrm{HN}$. Nitric oxide, on account of its low specific gravity, was likewise considered to be a binary compound of the formula NO. (N.S. 317.) Water, according to Gay-Lussac, is a compound of one volume of oxygen and two volumes of hydrogen. If wo assume one volume of hydrogen to contain 1000 atoms (molecules), then, if Dalton's formula $\mathrm{HO}$ is right, one volume of oxygen must contain 2000 atoms.

Nitric oxide is formed, according to Gay-Lussac, of one volume of nitrogen and one volume of oxygen. Therefore, if Dalton's formula $\mathrm{NO}$ is correct, one volume of nitrogen, like one volume of oxygen, must contain 2000 atoms. Hence we have :-

one volume of hydrogen 1000 atoms,
one volume of oxygen $2000 "$,
one volume of nitrogen $2000 "$,

Now Gay-Lussac asserts that ammonia is a compound of one volume of nitrogen and three volumes of hydrogenone volume of nitrogen 2000 atoms, three volumes of hydrogen 3000 "

and its formula would be $\mathrm{N}_{2} \mathrm{H}_{3}$ if Gay-Lussac's observations are correct.

Dalton's principle requires the formula $\mathrm{NH}$. Hence the alternative presented itself to Dalton either to reject his first principle or Gay-Lussac's observation. As the atomic theory p. 30 .

* R. 47. Grundzüge der theoretischen Chemie von Lothar Meyer, 1890, 
was strongly supported by experience he rejested GayLussac's law, and considered his own inaccurate observations to be correct and the more exact results of the French chemist to be faulty.

Some of the results of this investigation are :-

(1) Dalton was investigating the state of equilibrium in mixed gases in the year 1801. This investigation caused him to adopt the hypothesis $\mathrm{M} / \mathrm{S}=\mathrm{C}$.

(2) It is highly probable that the hypothesis $M / S=C$ and the observations of the proportions in which nitric oxide and oxygen combine led Dalton to the invention of his atomic theory.

(3 Atomistic views caused Dalton to abandon the hypothesis $\mathrm{M} / \mathrm{S}=\mathrm{C}$ in the year 1805 .

(4) If we remember that all theories in chemistry are of a provisional character, and that they are subject to changes in course of time, then we cannot deny our admiration to the great work of Dalton. It was be who first attempted to weigh molecules and atoms and measure their volumes.

XXXVII. Notices respecting New Books.

The Intellectual Rise in Electricity; a History. By Park BerJAMIN, Ph.D., LL.B. London: Longmans, 1895.

THE electrical properties of rubbed amber and the phenomena exhibited by the lodestone have been known since the very earliest historic times; their discovery was probably coeral with those of amber and lodestone. While the electrical fact remained for many centuries isolated and apparently useless, the orientation of suspended lodestone or of magnets derived from it soon suggested the mariner's compass and led to important advances in magnetic science, followed later by theories of attraction and repulsion. In the work before us Dr. Benjamin traces in a very interesting manner the development of these facts and theories up till the time of Franklin, when the recognition of electricity as a natural force led to its being more universally studied. The author bas searched among the manuscripts and books of many lands and all ages in order to find material for his history, and he has even been assisted by the labours of those who have investigated the ruins and records of ancient civilization in Phœnicia, Egypt, and Scandinavia. Such a search necessarily occupies many year's, and we owe its satisfactory termination to the author's patience and enthusiasm for his subject.

A very plausible theory is put forward to account for the introduction of the lodestone into Europe. It is supposed that the inhabitants of Cuntral Asia first became acquainted with its properties; migrating eastwards as Mongols they carried the knowledge into China, and travelling north-westward as Finns aud 